\title{
Da empiria ao campo de pesquisa: uma década de pesquisas do GESQ/PUC-Rio
}

\author{
João Carlos de Souza Anhaia Gino' \\ Secretaria Municipal de Educação do Rio de Janeiro, Professor \\ https://orcid.org/0000-0002-7452-0098
}

PAES DE CARVALHO, C.; OLIVEIRA, A. C. P. de; CANEDO, M. L. Gestão Escolar e Qualidade da Educação: caminhos e horizontes de pesquisa. Curitiba: Editora CRV, 2019.

Lançada no dia 3 de abril de 2019, em evento realizado na PUC-Rio, a obra Gestão escolar e qualidade da Educação: caminhos e horizontes de pesquisa foi organizada pelas professoras doutoras Cynthia Paes de Carvalho (PUC-Rio), Ana Cristina Prado de Oliveira (UNIRIO) e Maria Luiza Canedo (PUC-Rio). 0 livro é resultado do acúmulo de estudos desenvolvidos no Grupo de Pesquisas Gestão e Qualidade da Educação (GESQ/PUC-Rio), fundado em 2010 e liderado pela Prof. ${ }^{a}$ Dra. Cynthia Paes de Carvalho (PUC-Rio). A obra, publicada pela Editora CRV, é composta por 12 capítulos com artigos assinados por pesquisadores que fazem parte da trajetória do GESQ, além das contribuições dos professores doutores Ângelo Ricardo de Souza (UFPR) e Vandré Gomes da Silva (FCC), os quais possuem pesquisas que dialogam diretamente com algumas das áreas de interesse do Grupo.

Ao longo desse tempo, o GESQ esteve dedicado a trabalhar com dados da Prova Brasil e no desenvolvimento de surveys e estudos de caso em escolas e redes de ensino, buscando articular análises quantitativas às percepções dos agentes implementadores de políticas educacionais e seus possíveis reflexos nos resultados escolares. Várias das pesquisas realizadas pelo Grupo se dedicaram a associar metodologias quantitativas e qualitativas, em um esforço de produzir análises que possam partir do plano macro para uma visão micro dos contextos estudados. A presente obra aborda diversos aspectos da gestão escolar a partir de temas, como o clima escolar, os conselhos escolares, o uso de dados educacionais, as estratégias de escolha das instituições escolares pelas famílias, a colaboração docente, a liderança do diretor, a forma de provimento no cargo de diretor e as perspectivas de diretores e alunos com relação à aprendizagem e ao direito à educação.

Entre os 12 capítulos do livro, chama a atenção a importância dada pelas pesquisas à liderança do diretor enquanto um fator associado a melhoria do desempenho acadêmico dos estudantes. Entretanto, logo no primeiro capítulo, Cynthia Paes de Carvalho

Mestre em Educação pela Unirio; Doutorando em Educação pela PUC-Rio. 
e Ana Cristina P. de Oliveira reconhecem que essa liderança não está restrita apenas à figura do gestor escolar, mas à construção de uma cultura de liderança na escola. Tecendo uma rede de múltiplas lideranças, estimulando a colaboração e a participação da comunidade escolar e o envolvimento dos professores nas decisões pedagógicas da escola. Tais elementos proporcionam um clima escolar de satisfação e comprometimento do corpo docente, compartilhamento de responsabilidades e de estímulo à aprendizagem na escola. Destaca-se, na obra, os resultados de uma pesquisa, conduzida por Ana Cristina P. de Oliveira, que construiu indicadores que aferiram a liderança do diretor e a colaboração docente. Os resultados quantitativos do estudo apresentaram associação positiva desses indicadores com os resultados obtidos pelos estudantes das escolas do construto. Também em uma das pesquisas desenvolvidas no GESQ, identificou-se a percepção dos professores sobre o ambiente escolar como a variável de maior significância para o nível de satisfação dos professores, o que reforça a ideia de que algumas iniciativas e posicionamentos do diretor influenciam o clima escolar e interferem positivamente no trabalho dos professores.

As autoras do sexto capítulo, Ana Cristina P. de Oliveira e Marcela Fonseca, reconhecem, a partir das contribuições de Licínio Lima, que a gestão escolar ocorre mediante relações de disputa de poder entre os seus agentes, compreendendo a escola enquanto organização e sistema em si própria. 0 diretor, enquanto alguém que exercita o papel de líder perante os demais sujeitos escolares, acaba tendo que equilibrar interesses e exercitar constantemente a sua capacidade de adaptação. A liderança escolar, definida por Leithwood, está relacionada à capacidade de mobilização e influência sobre o grupo tendo em vista o alcance dos objetivos compartilhados pela escola. Diferentes são os perfis de liderança apresentados no capítulo, reconhecendo que a liderança efetiva é aquela que garante o foco da escola na aprendizagem, monitora as atividades escolares e o progresso dos alunos, apoia os professores, garante a participação dos pais, entre outras ações.

Contudo, algumas pesquisas apresentadas no livro apontam que os gestores escolares têm sido submetidos ao acúmulo de tarefas, especialmente as de cunho administrativo, sobrecarregando-os na função e afastando-os das discussões pedagógicas da escola. 0 que se configura em um problemático entrave para o exercício da liderança efetiva do diretor escolar, conforme mencionado no capítulo sete por Marina M. Meira, Ana Cristina P. de Oliveira e Marcela Fonseca, já que a construção de um ambiente escolar de aprendizagem está relacionada ao exercício da liderança pedagógica. Em levantamento de pesquisa apresentado no capítulo três, de autoria de Maria Luiza Canedo e Ana Luiza H. Sales, gestores escolares afirmavam que a concentração de tarefas de natureza administrativa era o primeiro dos seus desafios na escola, o que fez com que o desempenho acadêmico dos alunos ficasse em segundo lugar nesse "ranking" de prioridades. A situação é ainda mais alarmante quando os pesquisadores entrevistaram diretores com menos tempo no cargo, pois estes destacavam o desempenho escolar como o último dos seus desafios, 
estando atrás das tarefas administrativas, da gestão de pessoas e dos escassos recursos enfrentados pelas escolas.

0 capítulo quatro, assinado por Larissa Cruz e Carla Lima, apresenta resultados preocupantes com relação ao uso de dados educacionais nas escolas públicas de Macaé, no Estado do Rio de Janeiro, e em Juiz de Fora, no Estado de Minas Gerais. Nessa pesquisa, percebeu-se que as escolas, por não se apropriarem totalmente dos dados disponibilizados, perdem oportunidades importantes para a reflexão e o debate a respeito da aprendizagem dos alunos, visto que os dados podem trazer boas pistas daquilo que se tem avançado e retrocedido no trabalho pedagógico das escolas. Naquilo que as autoras da pesquisa conseguiram acompanhar sobre o uso de dados educacionais pela gestão das escolas, as ações acabaram sendo bastante pontuais e descontinuadas nas unidades escolares pesquisadas.

0 trabalho publicado pelo professor Ângelo Ricardo de Souza demonstra que, no Brasil, ainda temos a indicação como a principal forma de provimento no cargo de diretor escolar das redes públicas de ensino, apesar de essa situação já ter sido mais problemática no passado. Foi destacado o crescimento considerável no País dos conselhos escolares e da existência dos projetos político-pedagógicos (PPP) nas escolas, algo já previsto desde a LDBEN/1996. Porém, a simples existência desses instrumentos não garante o avanço no processo de democratização da gestão escolar. Até porque, como bem lembrou o capítulo assinado pelo professor Vandré Gomes da Silva, o PPP, enquanto um esforço coletivo, precisa partir de práticas concretas e não apenas como uma retórica. Já no caso dos conselhos escolares, o capítulo nove, de autoria de Maria de Fátima Lima e Maria Luiza Canedo, apontou para os resultados de uma pesquisa na rede municipal do Rio de Janeiro em que se percebeu a ausência de reuniões do conselho escolar nas escolas, a manutenção de graus de hierarquia entre os conselheiros, a influência de diretores e professores sobre os alunos conselheiros, a pouca participação dos pais e a redução de suas potencialidades à discussão financeira e ao seu caráter fiscalizador. Essas pesquisas evidenciam que, apesar de o Brasil ter avançado nas garantias legais para os instrumentos da gestão democrática da educação pública, o processo de democratização da organização da escola é extremamente complexo e espinhoso, haja vista as tradições políticas nada democráticas do País.

Gestão escolar e qualidade da Educação: caminhos e horizontes de pesquisa é uma espécie de leitura obrigatória para todos aqueles que pretendem conhecer com mais detalhes o trabalho desenvolvido pelo GESQ/PUC-Rio. As organizadoras da obra tiveram o êxito de conseguir reunir artigos que apresentam resultados de pesquisas que clarificam ao leitor as áreas de interesse do Grupo ao longo dos seus nove primeiros anos de existência. Além disso, o livro é bastante atual e dialoga diretamente com uma série de questões que estão na ordem do dia das escolas públicas brasileiras. A obra se afasta de um enfoque 
mais abrangente e excessivamente teórico, o que não significa dizer que os artigos da coletânea abrem mão dos referenciais teóricos em seus estudos. A opção por promover pesquisas com evidências empíricas em associação a resultados qualitativos extraídos nos campos de pesquisa permitiu aos pesquisadores do GESQ contribuir de forma consistente ao debate acadêmico e educacional, com achados importantes para uma série de desafios a serem encarados por gestores escolares sintonizados com uma educação democrática com qualidade e equidade.

Recebida em 1 de novembro de 2019

Aceita em 5 de abril de 2020

Publicada em 28 de agosto de 2020

Endereços para correspondência: Escola Municipal Dilermando Cruz - Avenida Teixeira de Castro, 407, 21040-010, Bonsucesso, Rio de Janeiro, Brasil; joao.gino87@gmail.com 